\title{
Reclassification of Subtercola pratensis Behrendt et al. 2002 as Agreia pratensis comb. nov.
}

Correspondence

Peter Schumann psc@dsmz.de

\author{
Peter Schumann, ${ }^{1}$ Undine Behrendt, ${ }^{2}$ Andreas Ulrich ${ }^{3}$ \\ and Ken-ichiro Suzuki ${ }^{4}$
}

\author{
'DSMZ - German Collection of Microorganisms and Cell Cultures, Mascheroder Weg 1b, \\ D-38124 Braunschweig, Germany \\ ${ }^{2}$ Centre for Agricultural Landscape and Land Use Research (ZALF), Institute of Primary \\ Production and Microbial Ecology, Gutshof 7, D-14641 Paulinenaue, Germany \\ ${ }^{3}$ Centre for Agricultural Landscape and Land Use Research (ZALF), Institute of Primary \\ Production and Microbial Ecology, Eberswalder Straße 84, D-15374 Müncheberg, Germany \\ ${ }^{4}$ Biological Resource Centre, Biotechnology Centre, National Institute of Technology and \\ Evaluation (NITE), Kazusa Academia Park, Kisarazu, Chiba 292-0812, Japan
}

Comparative analysis of $16 \mathrm{~S}$ rDNA sequences revealed a close phylogenetic relationship (99.6\% similarity) between Subtercola pratensis Behrendt et al. 2002 and Agreia bicolorata Evtushenko et al. 2001. The two species were found to share genus-specific chemotaxonomic characteristics such as the occurrence of D-ornithine and L-2,4-diaminobutyric acid in the peptidoglycan and the profile of cellular fatty acids and 1,1-dimethoxy-alkanes. DNA-DNA relatedness of only $47 \cdot 8 \%$ and differences in phenotypic features such as the menaquinone profile and oxidase and Voges-Proskauer reactions confirmed the distinct species status of $S$. pratensis and $A$. bicolorata. On the basis of the data from phylogenetic and phenotypic analyses, the reclassification of $S$. pratensis as Agreia pratensis comb. nov. is proposed. As a result of this reclassification, the two genera are coherent, in that the cell wall composition and 1,1-dimethoxy-alkane spectrum are significant genus-specific characteristics.
Studies of bacterial communities in various environments are now being performed increasingly fast by the application of techniques and approaches for determining genetic polymorphism. Novel taxa can be detected rapidly by the comparison of $16 \mathrm{~S}$ rDNA sequences with those of type strains available from comprehensive public databases. As result of this development, a multitude of new taxa are currently being proposed, and the probability of coincident submissions of manuscripts describing highly similar novel organisms is increasing.

Without being aware of the similarity of their research subjects, two research groups isolated strains of coryneform bacteria that contained a hitherto novel B-type peptidoglycan containing ornithine and 2,4-diaminobutyric acid (DAB). One group decided in favour of proposing the new genus Agreia to accommodate the isolates (Evtushenko et al., 2001), whereas the other submitted a proposal for a novel species of the phylogenetically closest genus Subtercola,

Published online ahead of print on 6 June 2003 as DOI 10.1099/ ijs.0.02664-0.

Abbreviations: DAB, 2,4-diaminobutyric acid; a-15:0 DMA, 1,1dimethoxy-anteiso-pentadecane; i-16:0 DMA, 1,1-dimethoxy-isohexadecane; a-17:0 DMA, 1,1-dimethoxy-anteiso-heptadecane.
Subtercola pratensis (Behrendt et al., 2002), during the review process of the description of Agreia. For obvious reasons, the type strains of Agreia bicolorata and S. pratensis could not be compared at that time. The taxonomic status of $A$. bicolorata and $S$. pratensis had to be reconsidered after valid publication of both names. The type strains A. bicolorata DSM $14575^{\mathrm{T}}$ and S. pratensis DSM $14246^{\mathrm{T}}$ were therefore subjected to supplementary chemotaxonomic studies, detailed phylogenetic analyses and DNA-DNA hybridization.

To clarify whether $S$. pratensis and A. bicolorata indeed display the same type of peptidoglycan, enantiomeric diamino acid isomers were determined according to Sasaki et al. (1998). The type strain of A. bicolorata and the type strain of $S$. pratensis contained both D-Orn and L-DAB in almost equal amounts in their cell walls and thus can be clearly differentiated from Subtercola boreus and Subtercola frigoramans, which contain only DAB in their peptidoglycan. S. pratensis and A. bicolorata display identical two-dimensional TLC patterns of peptides and amino acids resulting from partial hydrolysis (Schleifer, 1985) of the peptidoglycan (data not shown). Dinitrophenylation (Schleifer, 1985) of peptidoglycan samples of S. pratensis and A. bicolorata revealed free amino groups at Orn and 
DAB. Since position 3 of the peptide subunit of all known B-type peptidoglycan structures contains an L-isomeric amino acid (Schleifer \& Kandler, 1972; DSMZ, 2001), it may be concluded that L-DAB occupies position 3 of the peptide subunit and D-Orn is involved in the interpeptide bridge. Muramic acid residues of the peptidoglycans of both S. pratensis and A. bicolorata are acetylated, as determined according to Uchida et al. (1999). These results suggest that $S$. pratensis and A. bicolorata display the same peptidoglycan structure.

A further chemotaxonomic feature, the profiles of fatty acid methyl esters and 1,1-dimethoxy-alkanes of A. bicolorata and $S$. pratensis type strains, was analysed by GC and GC/MS according to Schumann et al. (1997). As shown in Table 1, similar patterns were found for the two strains. Supplementary to the report of Evtushenko et al. (2001), it was found that A. bicolorata also contained 1,1-dimethoxyanteiso-pentadecane (a-15:0 DMA). Comparison of profiles with those of $S$. boreus and S. pratensis (Männistö et al., 2000) revealed a similar spectrum for iso- and anteisobranched fatty acids, but differences were found in the composition of 1,1-dimethyl-alkanes. In addition to a-15:0 DMA, 1,1-dimethoxy-iso-hexadecane (i-16:0 DMA) and 1,1-dimethoxy-anteiso-heptadecane (a-17:0 DMA) constitute the predominant 1,1-dimethyl-alkanes of $S$. boreus and S. frigoramans (Table 1). Accordingly, the 1,1-dimethoxyalkane profile is an additional chemotaxonomic feature useful for discrimination of the genera Agreia and Subtercola.

Table 1. Fatty acid composition of $A$. bicolorata, S. pratensis, $S$. frigoramans and $S$. boreus

Values are percentages of total fatty acids. Strains: 1, A. bicolorata VKM Ac- $1804^{\mathrm{T}}$; 2, S. pratensis DSM $14642^{\mathrm{T}}$; 3, S. frigoramans DSM $13057^{\mathrm{T}}$; 4, S. boreus DSM $13056^{\mathrm{T}}$. Data for S. frigoramans and $S$. boreus were taken from Männistö et al. (2000). The growth temperature was $25^{\circ} \mathrm{C}$. $\operatorname{tr}$, Trace amount $(<1 \%)$.

\begin{tabular}{|lcccc|}
\hline Fatty acid & $\mathbf{1}$ & $\mathbf{2}$ & $\mathbf{3}$ & $\mathbf{4}$ \\
\hline $14: 0$ & - & $0 \cdot 25$ & - & - \\
$16: 0$ & $2 \cdot 66$ & $5 \cdot 22$ & - & - \\
$\mathrm{i}-14: 0$ & $1 \cdot 60$ & $0 \cdot 53$ & $6 \cdot 7$ & $\operatorname{tr}$ \\
$\mathrm{i}-15: 0$ & $1 \cdot 02$ & $1 \cdot 00$ & $\operatorname{tr}$ & $4 \cdot 3$ \\
$\mathrm{i}-16: 0$ & $30 \cdot 09$ & $17 \cdot 23$ & $10 \cdot 2$ & $4 \cdot 2$ \\
$\mathrm{i}-17: 0$ & - & $0 \cdot 51$ & - & - \\
a-15:0 & $48 \cdot 07$ & $46 \cdot 71$ & $46 \cdot 1$ & $51 \cdot 6$ \\
a-17:0 & $14 \cdot 43$ & $22 \cdot 15$ & $6 \cdot 8$ & $3 \cdot 5$ \\
a-15: & - & - & - & $\operatorname{tr}$ \\
$16: 0$ DMA & - & - & - & $\operatorname{tr}$ \\
i-15:0 DMA & - & - & - & $1 \cdot 7$ \\
i-16:0 DMA & - & - & $13 \cdot 3$ & $11 \cdot 9$ \\
a-15:0 DMA & $2 \cdot 13$ & $4 \cdot 17$ & $10 \cdot 3$ & $11 \cdot 0$ \\
a-17:0 DMA & - & - & $2 \cdot 9$ & $4 \cdot 0$ \\
Unknown & - & $2 \cdot 22$ & $2 \cdot 1$ & $4 \cdot 6$ \\
\hline
\end{tabular}

Analysis of the phylogenetic relationship between species of the genera Agreia and Subtercola, on the basis of $16 \mathrm{~S}$ rDNA sequences, was performed as described by Behrendt et al. (2002). S. pratensis clustered with A. bicolorata with both the neighbour-joining and maximum-likelihood methods, displaying the high sequence similarity of $99.6 \%$ (Figs 1 and 2). This branch was supported by a high bootstrap value, as was the clustering of both with S. boreus and $S$. frigoramans. However, the originally described species S. boreus and S. frigoramans (Männistö et al., 2000) did not form a monophyletic branch. The similarity of $S$. boreus to $S$. pratensis and A. bicolorata was up to $1 \%$ higher than its similarity to $S$. frigoramans. Moreover, clustering of S. frigoramans and S. boreus, as shown in Fig. 1, was not supported by bootstrap analysis and could not be confirmed by either the maximum-likelihood method (Fig. 2) or the consensus tree, according to Felsenstein (1993). These results show that the genera Subtercola and Agreia cannot be differentiated unambiguously on the basis of phylogenetic analyses. A comprehensive phylogenetic comparison of the two genera could not be performed by Evtushenko et al. (2001) since the publication of the genus Subtercola and the review process of the description of the genus Agreia coincided.

On the basis of the aforementioned results, it appears reasonable to affiliate strain DSM $14246^{\mathrm{T}}$ to the genus Agreia. However, it remained to be investigated whether strain DSM $14246^{\mathrm{T}}$ represents an individual species or whether it is a strain of A. bicolorata. The intraspecific relationship of the type strains of $S$. pratensis and $A$. bicolorata was examined by DNA-DNA hybridization using $2 \times$ SSC containing $10 \%(\mathrm{v} / \mathrm{v})$ DMSO as hybridization buffer at $68^{\circ} \mathrm{C}$ (Escara \& Hutton, 1980; Huß et al., 1983; Jahnke, 1992). The DNA-DNA relatedness of the type strains DSM $14246^{\mathrm{T}}$ and DSM $14575^{\mathrm{T}}$ was found to be $47 \cdot 8 \%$. The finding that the two type strains represent different genomospecies according to Wayne et al. (1987) is supported by several differentiating phenotypic features. In contrast to $S$. pratensis, cells of A. bicolorata are motile and positive for the oxidase and Voges-Proskauer reactions. Furthermore, the isoprenoid quinones of A. bicolorata are dominated by MK-10, whereas those of $S$. pratensis predominantly comprise MK-10 and MK-11.

The polyphasic approach to the definition of a new genus is based on consideration of both phylogenetic relationships and phenotypic properties. When $16 \mathrm{~S}$ rDNA sequence comparison and chemotaxonomic analyses provide discordant results, selection of the decisive dataset requires taxonomic expertise. The unification of the genera Microbacterium (containing Lys in the peptidoglycan) and Aureobacterium (containing Orn in the peptidoglycan) by Takeuchi \& Hatano (1998) is an example of attributing priority to analyses of partial $16 \mathrm{~S}$ rDNA sequence similarity for genus allocation. On the other hand, the recent reevaluation of the genus status of Oerskovia (unified earlier with the phylogenetically related genus Cellulomonas) by 


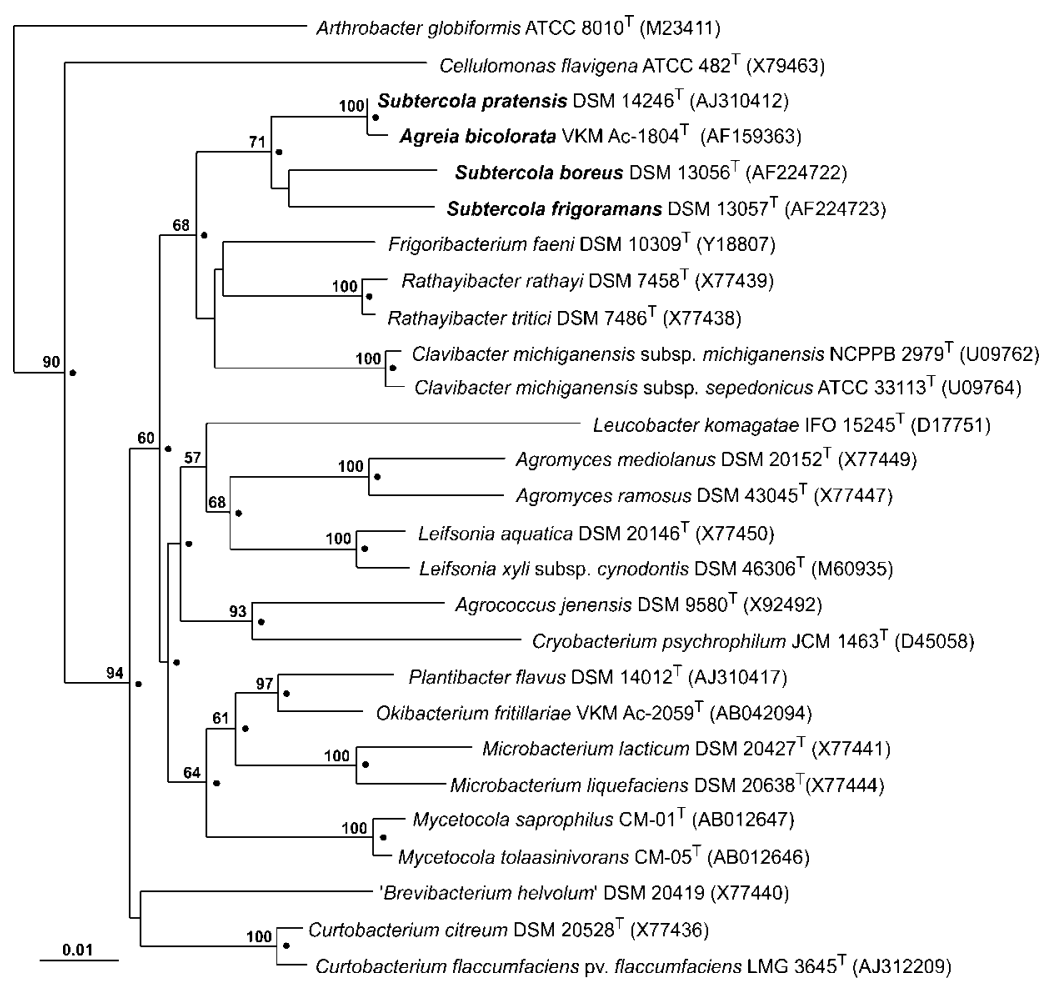

Fig. 1. Phylogenetic tree showing the relationships of Subtercola and Agreia species within the family Microbacteriaceae. The tree is based on a $1486 \mathrm{bp}$ alignment of $16 \mathrm{~S}$ rDNA sequences and was constructed using the neighbour-joining method (Saitou \& Nei, 1987). Dots indicate branches of the tree that were also formed using the maximumlikelihood method (Felsenstein, 1981). To estimate the root position of the tree, Brevibacterium linens ATCC $9172^{\top}$ (X77451) was used as an outgroup. Each value is the number of times that a branch appeared in 100 bootstrap replications. The bar indicates the relative sequence divergence.
Stackebrandt et al. (2002) showed that genus-specific chemotaxonomic features can also be of greater concern when defining a genus. Thus, the close phylogenetic relationship but low DNA-DNA relatedness of $S$. pratensis and A. bicolorata and the clear differentiation of both from the original psychrophilic species of Subtercola on the basis of chemotaxonomic features support the separate genus status of Agreia and, hence, we propose the reclassification of $S$. pratensis as Agreia pratensis comb. nov.

\section{Description of Agreia pratensis (Behrendt et al. 2002) comb. nov.}

Agreia pratensis (pra.ten'sis. L. fem. adj. pratensis pertaining to meadows/grassland).

Basonym: Subtercola pratensis Behrendt et al. 2002.

The description is as given by Behrendt et al. (2002). The type strain is DSM $14246^{\mathrm{T}}\left(=\mathrm{P} 229 / 10^{\mathrm{T}}=\mathrm{LMG} 21000^{\mathrm{T}}\right)$.

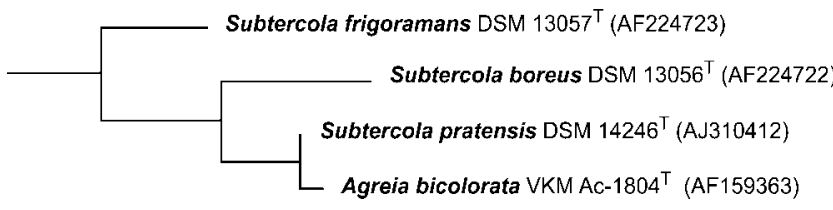

Fig. 2. Part of the maximum-likelihood tree showing the relationship between Subtercola and Agreia species. The tree is based on $1486 \mathrm{bp}$ and was constructed using the DNAML program (Felsenstein, 1993).

\section{Acknowledgements}

We wish to thank Mr M. Chijimatsu (RIKEN, Saitama, Japan) for analysis of cell wall amino acid composition and Mrs B. Sträubler (DSMZ, Braunschweig, Germany) for DNA-DNA hybridization studies.

\section{References}

Behrendt, U., Ulrich, A., Schumann, P., Naumann, D. \& Suzuki, K. (2002). Diversity of grass-associated Microbacteriaceae isolated from the phyllosphere and litter layer after mulching the sward; polyphasic characterization of Subtercola pratensis sp. nov., Curtobacterium herbarum sp. nov. and Plantibacter flavus gen. nov., sp. nov. Int J Syst Evol Microbiol 52, 1441-1454.

DSMZ (2001). Catalogue of Strains, 7th edn. Braunschweig: Deutsche Sammlung von Mikroorganismen und Zellkulturen.

Escara, J. F. \& Hutton, J. R. (1980). Thermal stability and renaturation of DNA in dimethyl sulfoxide solutions: acceleration of the renaturation rate. Biopolymers 19, 1315-1327.

Evtushenko, L. I., Dorofeeva, L. V., Dobrovolskaya, T. G., Streshinskaya, G. M., Subbotin, S. A. \& Tiedje, J. M. (2001). Agreia bicolorata gen. nov., sp. nov., to accommodate actinobacteria isolated from narrow reed grass infected by the nematode Heteroanguina graminophila. Int J Syst Evol Microbiol 51, 2073-2079.

Felsenstein, J. (1981). Evolutionary trees from DNA sequences: a maximum likelihood approach. J Mol Evol 17, 368-376.

Felsenstein, J. (1993). PHYLIP (Phylogeny Interference Package), version 3.5c. Distributed by the author. Department of Genetics, University of Washington, Seattle, USA.

Huß, V. A. R., Festl, H. \& Schleifer, K. H. (1983). Studies on the spectrophotometric determination of DNA hybridization from renaturation rates. Syst Appl Microbiol 4, 184-192. 
Jahnke, K. D. (1992). Basic computer program for evaluation of spectroscopic DNA renaturation data from GILFORD System 2600 spectrometer on a PC/XT/AT type personal computer. J Microbiol Methods 15, 61-73.

Männistö, M. K., Schumann, P., Rainey, F. A., Kämpfer, P., Tsitko, I., Tiirola, M. A. \& Salkinoja-Salonen, M. S. (2000). Subtercola boreus gen. nov., sp. nov. and Subtercola frigoramans sp. nov., two new psychrophilic actinobacteria isolated from boreal groundwater. Int J Syst Evol Microbiol 50, 1731-1739.

Saitou, N. \& Nei, M. (1987). The neighbor-joining method: a new method for reconstructing phylogenetic trees. Mol Biol Evol 4, 406-425.

Sasaki, J., Chijimatsu, M. \& Suzuki, K. (1998). Taxonomic significance of 2,4-diaminobutyric acid isomers in the cell wall peptidoglycan of actinomycetes and reclassification of Clavibacter toxicus as Rathayibacter toxicus comb. nov. Int J Syst Bacteriol 48, 403-410.

Schleifer, K. H. (1985). Analysis of the chemical composition and primary structure of murein. Methods Microbiol 18, 123-156.

Schleifer, K. H. \& Kandler, O. (1972). Peptidoglycan types of bacterial cell walls and their taxonomic implications. Bacteriol Rev 36, 407-477.
Schumann, P., Prauser, H., Rainey, F. A., Stackebrandt, E. \& Hirsch, P. (1997). Friedmanniella antarctica gen. nov., sp. nov, an LL-diaminopimelic acid-containing actinomycete from Antarctic sandstone. Int J Syst Bacteriol 47, 278-283.

Stackebrandt, E., Breymann, S., Steiner, U., Prauser, H., Weiss, N. \& Schumann, P. (2002). Re-evaluation of the status of the genus Oerskovia, reclassification of Promicromonospora enterophila (Jáger et al. 1983) as Oerskovia enterophila comb. nov. and description of Oerskovia jenensis sp. nov. and Oerskovia paurometabola sp. nov. Int J Syst Evol Microbiol 52, 1105-1111.

Takeuchi, M. \& Hatano, K. (1998). Union of the genera Microbacterium Orla-Jensen and Aureobacterium Collins et al. in a redefined genus Microbacterium. Int J Syst Bacteriol 48, 739-747.

Uchida, K., Kudo, T., Suzuki, K. \& Nakase, T. (1999). A new rapid method of glycolate test by diethyl ether extraction, which is applicable to a small amount of bacterial cells of less than one milligram. J Gen Appl Microbiol 45, 49-56.

Wayne, L. G., Brenner, D. J., Colwell, R. R. \& 9 other authors (1987) International Committee on Systematic Bacteriology. Report of the ad hoc committee on reconciliation of approaches to bacterial systematics. Int J Syst Bacteriol 37, 463-464. 